common mental disorders, such as depression, are similar across cultures ${ }^{8}$ and that no important culturespecific symptoms or presentations would be missed. The charges of ethnocentricity can be reduced by assessing the instrument's performance and acceptability within a new population. This may require adaptations to the standard instrument. The general health questionnaire has been extensively validated in other cultures, ${ }^{9}$ but not specifically with an African Caribbean population in the United Kingdom.

The etic method allows for comparisons between cultural groups. However, if supposedly universal symptoms do not occur in a particular cultural group or do not have the same meaning the result will be invalid and misleading.

Shaw et al used an etic approach to screen for and identify cases and then interviewed these cases with an emic schedule. People whom the initial instruments failed to recognise as distressed would have been missed. By only interviewing identified cases the authors may have lost rich information on cultural aspects of mental health. This is important for those working in primary care, where most people with mental illness are seen and cared for, and where the iceberg of unmet need almost certainly lies.

The authors have attempted a difficult study and provided some insights into mental health problems in different cultural groups. However, prevalences derived from such a heterogeneous sample may conceal important variations among subgroups. Counting heads is important, but further attention must be given to the complexity of cultural and social factors in the experience of mental illness.

Senior P, Bhopal R. Ethnicity as a variable in epiden BMJ 1994;309:327-30.

2 Office of Population Censuses and Surveys. 1991 census:local base statistics. London: OPCS, 1992.

3 Bracken P, Greenslade L, Griffin B, Smythe M. Mental health and ethnicity: an Irish dimension. Br J Psychiatry 1998;172:103-5.

4 McKenzie K, Crowcroft NS. Describing race, ethnicity and culture in medical science. $B M J$ 1996;312:1054.

5 Smaje C. Ethnicity in context. In: Smaje C, ed. Health, race and ethnicity. London: King's Fund Institute, 1995.

6 Kleinman A. Anthropology and psychiatry. The role of culture in cross-cultural research. Br J Psychiatry 1987;151:447-54.

7 Abas M, Phillips C, Richards M, Carter J, Levy R. Initial development of a new culture-specific screen for emotional distress in older Caribbean people. Int J Ger Psychiatry 1996;11:1097-103.

8 Marsella A. Thoughts on cross-cultural studies on the epidemiology of depression. Culture, Medicine and Psychiatry 1978;2:343-57.

9 Jacob, K, Bhugra D, Mann A. The validation of the 12-item general health questionnaire among ethnic Indians living in the United Kingdom. Psychol Med 1997;27:1215-7.

\title{
Retrospective analysis of census data on general practitioners who qualified in South Asia: who will replace them as they retire?
}

Donald H Taylor Jr, Aneez Esmail

Center for Health

Policy, Law and

Management, Box

90253, Duke

University, Durham,

NC 27708, USA

Donald H Taylor Jr, assistant research professor

Harvard Medical School, Cambridge, MA 0211, USA

Aneez Esmail, visiting professor of social medicine

Correspondence to: Dr Taylor dtaylor@hpolicy. duke.edu

BMJ 1999;318:306-10

\author{
Abstract \\ Objectives To determine the number and \\ geographical distribution of general practitioners in \\ the NHS who qualified medically in South Asia and to \\ project their numbers as they retire. \\ Design Retrospective analysis of yearly data and \\ projection of future trends. \\ Setting England and Wales. \\ Subjects General practitioners who qualified \\ medically in the countries of Bangladesh, India, \\ Pakistan, and Sri Lanka and who were practising in \\ the NHS on 1 October 1992. \\ Main outcome measures Proportion and age of \\ general practitioners who qualified in South Asia by \\ health authority; the Benzeval and Judge measure of \\ population need at the health authority level. \\ Results 4192 of 25333 (16.5\%) of all unrestricted \\ general practitioners practising full time on 1 October \\ 1992 qualified in South Asian medical schools. The \\ proportion varied by health authority from $0.007 \%$ to \\ $56.5 \%$. Roughly two thirds who were practising in \\ 1992 will have retired by 2007; in some health \\ authorities this will represent a loss of one in four \\ general practitioners. The practices that these doctors \\ will leave seem to be in relatively deprived areas as \\ measured by deprivation payments and a health \\ authority measure of population need.
}

Conclusion Many general practitioners who qualified in South Asian medical schools will retire within the next decade. The impact will vary greatly by health authority. Those health authorities with the greatest number of such doctors are in some of the most deprived areas in the United Kingdom and have experienced the most difficulty in filling vacancies. Various responses will be required by workforce planners to mitigate the impact of these retirements.

\section{Introduction}

There is concern in some circles that the future supply of general practitioners will be inadequate to meet the needs of an NHS led by primary care. ${ }^{12}$ Others are not convinced and note a lack of definitive evidence. ${ }^{3}$ Many of the issues relate to changes in the career paths of general practitioners, particularly young ones. ${ }^{4-9}$ Decreased popularity of general practice as a career choice,${ }^{6}{ }^{10}$ drop outs from medical school, ${ }^{11}{ }^{12}$ and early exits from practice by young general practitioners ${ }^{7}$ are some of the key issues.

Another issue that will influence the future supply of general practitioners is the expected retirement of doctors who qualified in South Asian medical schools (in Bangladesh, India, Pakistan, and Sri Lanka) and emigrated to the United Kingdom in the 1960s and 1970 s primarily to fill a perceived staff shortage in an 
expanding NHS. Many of these doctors became general practitioners, and many will be retiring in the next decade. Because of changes in the regulations of medical licensure in the United Kingdom, doctors from South Asian medical schools can no longer be expected to fill general practitioner partnership posts in large numbers, if at all. It is unclear from present evidence whether filling these posts will be particularly difficult, but there is anecdotal evidence that many of them are not likely to be viewed as attractive practice opportunities because of large list sizes and relatively deprived practice populations, especially to young general practitioners moving into the NHS. ${ }^{8}$

To provide insight into how difficult these posts may be to fill in the future we identified the proportion of general practitioners practising in 1992 who qualified in South Asian medical schools by health authority and projected the future number of such doctors as they retire. We have described health authorities by their population need and expected impact of retirements among South Asian qualified general practitioners.

\section{Methods}

This study is based on data from the general practitioner census, a secondary database that provides a comprehensive data source to study changes in the general practitioner workforce. These data contain information on all qualified general practitioners in England and Wales and are aggregated by the General Medical Services Statistics Division of the NHS Executive (which collects information from health authorities). They have been used in previous studies on the health workforce. ${ }^{73}{ }^{14}$ For the years 1990-2 one of the variables collected was country of medical qualification, allowing us to determine the proportion of South Asian qualifiers by health authority. South Asian qualifiers were defined as those doctors medically qualifying in the countries of Bangladesh, India, Pakistan, and Sri Lanka. After 1 October 1992 this variable was no longer collected, but we could track general practitioners identified as being South Asian qualifiers in 1992 over time because of the unique identification number each doctor in the database received.

\begin{tabular}{|c|c|c|c|c|c|}
\hline Family health services authority & 1992 & 1997 & 2002 & 2007 & Difference 2007-1992 (\%) \\
\hline Barking and Havering & $100(56.50)$ & $98(55.37)$ & $78(44.07)$ & $52(29.38)$ & -27.12 \\
\hline Redbridge and Waltham Forest & $93(43.87)$ & $86(40.57)$ & $69(32.55)$ & $43(20.28)$ & -23.58 \\
\hline Walsall & $65(51.59)$ & $63(50.00)$ & $60(47.62)$ & $38(30.16)$ & -21.43 \\
\hline Barnsley & $39(38.24)$ & $39(38.24)$ & $38(37.25)$ & $19(18.63)$ & -19.61 \\
\hline Wales 5 & $126(43.90)$ & $120(41.81)$ & $113(39.37)$ & $70(24.39)$ & -19.51 \\
\hline Salford & $45(37.50)$ & $44(36.67)$ & $36(30.00)$ & $24(20.00)$ & -17.50 \\
\hline City and East London & $139(42.25)$ & $132(40.12)$ & $111(33.74)$ & $82(24.92)$ & -17.33 \\
\hline Brent and Harrow & $92(36.08)$ & $86(33.73)$ & $78(30.59)$ & $48(18.82)$ & -17.25 \\
\hline Wigan & $60(43.80)$ & $57(41.61)$ & $50(36.50)$ & $37(27.01)$ & -16.79 \\
\hline Doncaster & $41(28.67)$ & $39(27.27)$ & $35(24.48)$ & $17(11.89)$ & -16.78 \\
\hline Manchester & $69(30.00)$ & $67(29.13)$ & $55(23.91)$ & $31(13.48)$ & -16.52 \\
\hline Sandwell & $62(43.36)$ & $59(41.26)$ & $54(37.76)$ & $39(27.27)$ & -16.08 \\
\hline Enfield and Haringey & $88(34.11)$ & $82(31.78)$ & $74(28.68)$ & $47(18.22)$ & -15.89 \\
\hline Rotherham & $29(27.10)$ & $27(25.23)$ & $26(24.30)$ & $12(11.21)$ & -15.89 \\
\hline Hillingdon & $42(36.52)$ & $41(35.65)$ & $37(32.17)$ & $24(20.87)$ & -15.65 \\
\hline Croydon & $45(28.13)$ & $44(27.50)$ & $33(20.63)$ & $20(12.50)$ & -15.63 \\
\hline Rochdale & $27(27.84)$ & $25(25.77)$ & $21(21.65)$ & $12(12.37)$ & -15.46 \\
\hline Greenwich and Bexley & $77(39.09)$ & $73(37.06)$ & $66(33.50)$ & $47(23.86)$ & -15.23 \\
\hline Sunderland & $43(31.85)$ & $43(31.85)$ & $35(25.93)$ & $23(17.04)$ & -14.81 \\
\hline Kirklees & $46(25.84)$ & $44(24.72)$ & $40(22.47)$ & $20(11.24)$ & -14.61 \\
\hline Coventry & $42(26.58)$ & $41(25.95)$ & $31(19.62)$ & $19(12.03)$ & -14.56 \\
\hline Merton, Sutton, and Wandsworth & $67(22.95)$ & $63(21.58)$ & $49(16.78)$ & $26(8.90)$ & -14.04 \\
\hline Wolverhampton & $45(36.89)$ & $45(36.89)$ & $41(33.61)$ & $28(22.95)$ & -13.93 \\
\hline Wales 3 & $65(29.41)$ & $64(28.96)$ & $59(26.70)$ & $35(15.84)$ & -13.57 \\
\hline Birmingham & $154(29.79)$ & $150(29.01)$ & $135(26.11)$ & $87(16.83)$ & -12.96 \\
\hline Bury & $22(25.88)$ & $22(25.88)$ & $20(23.53)$ & $11(12.94)$ & -12.94 \\
\hline Lambeth, Southwark, and Lewisham & $101(26.65)$ & $95(25.07)$ & $78(20.58)$ & $53(13.98)$ & -12.66 \\
\hline Humberside & $103(24.24)$ & $100(23.53)$ & $91(21.41)$ & $50(11.76)$ & -12.47 \\
\hline Wakefield & $32(20.13)$ & $30(18.87)$ & $26(16.35)$ & $13(8.18)$ & -11.95 \\
\hline Oldham & $32(31.68)$ & $32(31.68)$ & $29(28.71)$ & $20(19.80)$ & -11.88 \\
\hline Staffordshire & $129(26.93)$ & $122(25.47)$ & $107(22.34)$ & $73(15.24)$ & -11.69 \\
\hline Ealing, Hammersmith, and Hounslow & $99(28.70)$ & $94(27.25)$ & $81(23.48)$ & $59(17.10)$ & -11.59 \\
\hline Tameside & $27(26.73)$ & $27(26.73)$ & $23(22.77)$ & $16(15.84)$ & -10.89 \\
\hline Lancashire & $172(24.93)$ & 171 (24.78) & $155(22.46)$ & 100 (14.49) & -10.43 \\
\hline South Tyneside & $21(26.92)$ & $20(25.64)$ & $16(20.51)$ & $13(16.67)$ & -10.26 \\
\hline Liverpool & $78(35.45)$ & 75 (34.09) & $71(32.27)$ & $56(25.45)$ & -10.00 \\
\hline Nottinghamshire & $94(20.35)$ & $91(19.70)$ & $84(18.18)$ & $49(10.61)$ & -9.74 \\
\hline Kent & $159(20.60)$ & 152 (19.69) & $144(18.65)$ & $86(11.14)$ & -9.46 \\
\hline Dudley & 30 (22.22) & $29(21.48)$ & $26(19.26)$ & $18(13.33)$ & -8.89 \\
\hline Essex & $161(22.09)$ & $154(21.12)$ & $144(19.75)$ & $99(13.58)$ & -8.50 \\
\hline Sheffield & $37(13.50)$ & $37(13.50)$ & $33(12.04)$ & $14(5.11)$ & -8.39 \\
\hline Calderdale & $17(19.77)$ & $16(18.60)$ & $14(16.28)$ & $10(11.63)$ & -8.14 \\
\hline
\end{tabular}




\begin{tabular}{|c|c|c|c|c|c|}
\hline Family health services authority & 1992 & 1997 & 2002 & 2007 & Difference 2007-1992 (\%) \\
\hline Camden and Islington & $26(13.68)$ & $26(13.68)$ & $17(8.95)$ & $11(5.79)$ & -7.89 \\
\hline Barnet & $25(14.88)$ & $23(13.69)$ & $21(12.50)$ & $12(7.14)$ & -7.74 \\
\hline Leeds & $48(13.75)$ & $47(13.47)$ & $39(11.17)$ & $22(6.30)$ & -7.45 \\
\hline Derbyshire & $70(15.28)$ & $68(14.85)$ & $62(13.54)$ & $37(8.08)$ & -7.21 \\
\hline St Helens and Knowsley & $44(26.04)$ & $43(25.44)$ & $41(24.26)$ & $32(18.93)$ & -7.10 \\
\hline Bromley & $27(19.01)$ & $25(17.61)$ & $24(16.90)$ & $17(11.97)$ & -7.04 \\
\hline Solihull & $15(14.42)$ & 15 (14.42) & $13(12.50)$ & $8(7.69)$ & -6.73 \\
\hline Warwickshire & $37(15.04)$ & 35 (14.23) & $31(12.60)$ & $21(8.54)$ & -6.50 \\
\hline Bolton & $32(25.00)$ & $30(23.44)$ & $27(21.09)$ & $24(18.75)$ & -6.25 \\
\hline Cleveland & $41(15.89)$ & 39 (15.12) & 37 (14.34) & $26(10.08)$ & -5.81 \\
\hline Trafford & $13(12.50)$ & $12(11.54)$ & $11(10.58)$ & $7(6.73)$ & -5.77 \\
\hline Leicestershire & $67(15.30)$ & $63(14.38)$ & $58(13.24)$ & $42(9.59)$ & -5.71 \\
\hline Bradford & $41(17.75)$ & $41(17.75)$ & $39(16.88)$ & $28(12.12)$ & -5.63 \\
\hline Gateshead & $21(19.63)$ & $20(18.69)$ & $20(18.69)$ & $15(14.02)$ & -5.61 \\
\hline Durham & 39 (13.49) & $37(12.80)$ & $36(12.46)$ & $23(7.96)$ & -5.54 \\
\hline Sefton & $17(12.23)$ & $17(12.23)$ & $17(12.23)$ & $10(7.19)$ & -5.04 \\
\hline Stockport & $16(11.43)$ & $16(11.43)$ & $14(10.00)$ & $9(6.43)$ & -5.00 \\
\hline Newcastle upon Tyne & $13(9.22)$ & $12(8.51)$ & $12(8.51)$ & $6(4.26)$ & -4.96 \\
\hline Bedfordshire & $43(16.23)$ & $41(15.47)$ & 38 (14.34) & 30 (11.32) & -4.91 \\
\hline Shropshire & $17(8.54)$ & $17(8.54)$ & $14(7.04)$ & $8(4.02)$ & -4.52 \\
\hline Wales 1 & $26(12.56)$ & 26 (12.56) & $24(11.59)$ & $17(8.21)$ & -4.35 \\
\hline North Tyneside & $11(11.46)$ & $10(10.42)$ & $10(10.42)$ & $7(7.29)$ & -4.17 \\
\hline Kingston and Richmond & $16(10.96)$ & $16(10.96)$ & $15(10.27)$ & $10(6.85)$ & -4.11 \\
\hline Cheshire & $42(8.90)$ & $39(8.26)$ & $36(7.63)$ & $23(4.87)$ & -4.03 \\
\hline Northamptonshire & $24(8.96)$ & $24(8.96)$ & $23(8.58)$ & $14(5.22)$ & -3.73 \\
\hline Kensington, Chelsea, and Westminster & $18(10.59)$ & $16(9.41)$ & $15(8.82)$ & $12(7.06)$ & -3.53 \\
\hline Berkshire & $36(10.14)$ & $35(9.86)$ & $33(9.30)$ & $24(6.76)$ & -3.38 \\
\hline Hertfordshire & $40(7.94)$ & $37(7.34)$ & $33(6.55)$ & $23(4.56)$ & -3.37 \\
\hline Lincolnshire & $17(5.70)$ & $16(5.37)$ & $11(3.69)$ & $7(2.35)$ & -3.36 \\
\hline Wales 7 & $14(6.60)$ & $14(6.60)$ & $14(6.60)$ & $7(3.30)$ & -3.30 \\
\hline East Sussex & $21(5.69)$ & $21(5.69)$ & $17(4.61)$ & $9(2.44)$ & -3.25 \\
\hline Wales 8 & $18(9.68)$ & $18(9.68)$ & $17(9.14)$ & $12(6.45)$ & -3.23 \\
\hline Wirral & $24(14.12)$ & $24(14.12)$ & $24(14.12)$ & $19(11.18)$ & -2.94 \\
\hline Buckinghamshire & $30(9.46)$ & $28(8.83)$ & $26(8.20)$ & $21(6.62)$ & -2.84 \\
\hline Northumberland & $13(8.18)$ & $13(8.18)$ & $12(7.55)$ & $9(5.66)$ & -2.52 \\
\hline Wiltshire & $10(3.76)$ & $9(3.38)$ & $8(3.01)$ & $4(1.50)$ & -2.26 \\
\hline Wales 4 & $5(3.42)$ & $5(3.42)$ & $4(2.74)$ & $2(1.37)$ & -2.05 \\
\hline Wales 2 & $8(4.17)$ & $8(4.17)$ & $8(4.17)$ & $5(2.60)$ & -1.56 \\
\hline Hampshire & $23(2.97)$ & $21(2.71)$ & $18(2.33)$ & $11(1.42)$ & -1.55 \\
\hline Cambridgeshire & $20(6.10)$ & $19(5.79)$ & $19(5.79)$ & $15(4.57)$ & -1.52 \\
\hline Avon & $13(2.81)$ & $10(2.16)$ & $9(1.94)$ & $6(1.30)$ & -1.51 \\
\hline Surrey & $17(3.45)$ & $17(3.45)$ & $15(3.04)$ & $10(2.03)$ & -1.42 \\
\hline Wales 6 & $2(2.63)$ & $2(2.63)$ & $1(1.32)$ & $1(1.32)$ & -1.32 \\
\hline Cumbria & $10(3.86)$ & $10(3.86)$ & $10(3.86)$ & $7(2.70)$ & -1.16 \\
\hline Gloucestershire & $5(1.72)$ & $4(1.38)$ & $3(1.03)$ & $2(0.69)$ & -1.03 \\
\hline Suffolk & $10(3.14)$ & $10(3.14)$ & $10(3.14)$ & $7(2.20)$ & -0.94 \\
\hline Norfolk & $10(2.53)$ & $10(2.53)$ & $9(2.28)$ & $7(1.77)$ & -0.76 \\
\hline Devon & $7(1.29)$ & $7(1.29)$ & $6(1.11)$ & $3(0.55)$ & -0.74 \\
\hline North Yorkshire & $5(1.31)$ & $5(1.31)$ & $3(0.78)$ & $3(0.78)$ & -0.52 \\
\hline Cornwall and Isles of Scilly & $2(0.75)$ & $1(0.37)$ & $1(0.37)$ & $1(0.37)$ & -0.37 \\
\hline Hereford and Worcester & $6(1.83)$ & $6(1.83)$ & $6(1.83)$ & $5(1.53)$ & -0.31 \\
\hline Dorset & $5(1.47)$ & $5(1.47)$ & $5(1.47)$ & $4(1.18)$ & -0.29 \\
\hline West Sussex & $11(3.02)$ & $11(3.02)$ & $11(3.02)$ & $10(2.75)$ & -0.27 \\
\hline Isle of Wight & $1(1.47)$ & $1(1.47)$ & $1(1.47)$ & $1(1.47)$ & 0.00 \\
\hline Oxfordshire & $3(1.06)$ & $3(1.06)$ & $3(1.06)$ & $3(1.06)$ & 0.00 \\
\hline Somerset & $2(0.87)$ & $2(0.87)$ & $2(0.87)$ & $2(0.87)$ & 0.00 \\
\hline
\end{tabular}

${ }^{*}$ Table sorted by percentage change (1992 to 2007) in full time unrestricted general practitioners who qualified in South Asia; constant denominator assumed.

We also used the general practitioner census to calculate mean list size and the proportion of patients on a general practitioner's list who triggered deprivation payments (bands 1, 2, and 3 aggregated) as of 1 October 1992. The entire database covering 1990-4 was used to determine the mean retirement age over the period; we assumed that general practitioners who left practice at age 55 or older were retiring and would not return to practice. We projected the future supply of
South Asian qualifying general practitioners by health authority starting with the actual number of such doctors on 1 October 1992 and assumed that they would retire at the age of 63 , the mean retirement age of all general practitioners in 1990-4. Thus, we assumed that retirement age, on average, would not differ across ethnic groups. We assumed no net migration of South Asian general practitioners across health authorities, an assumption supported by past work. $^{73}$ We 
projected the number of South Asian qualifiers in 1997, 2002, and 2007. To calculate the proportion of NHS general practitioners represented by South Asian qualifiers in the future, we assumed a constant denominator equal to the total number of general practitioners in 1992; recent work has shown that the total number of whole time equivalent general practitioners in the workforce has remained relatively stable, despite the increase in the number of part timers entering general practice. ${ }^{7}$ We further assumed that no South Asian qualifying general practitioners will be recruited into general practice in the future.

We compared the proportion of general practitioners in a health authority who would be lost to retirement among South Asian general practitioners using the assumptions noted above to the relative need of the population at the health authority level using a recent measure of population need..$^{15}$ The Benzeval and Judge measure of population need at health authority level was developed from models estimated at the individual level that predict use of general practitioner services. Odds ratios for significant predictors of use were used to weight measures of variables at health authority level used in the model to develop an index. The all England mean was 2.0, with higher numbers representing greater population need. We obtained this health authority level measure from the authors of that study.

\section{Results}

Of the 25333 unrestricted general practitioners practising full time in the NHS on 1 October 1992, 4192 $(16.5 \%)$ qualified in South Asia; 2720 (64.9\%) of them were within 15 years of the mean retirement age (63 years) for all general practitioners over the period 1990-4 on 1 October 1992. On average, South Asian qualifiers had more patients on their medical lists who triggered deprivation payments (mean number $312.4 v$ 213.5; $\mathrm{P}<0.0001)$ from bands $1-3$ combined comparedwithothergeneralpractitioners.Therewasnodifference in average list size (unadjusted for list inflation) between South Asian qualifiers and all other general practitioners (2006 v 2017; $\mathrm{P}=0.33$ ). The proportion of general practitioners who qualified in South Asian medical schools varied by health authority from $0.007 \%$ to $56.5 \%$ on 1 October 1992 . The table ranks health authorities by the proportion of the practising general practitioners in 1992 who will be lost to projected retirement among South Asian qualifiers by the year 2007 (ranging from a 27.1\% loss in Barking and Havering to no loss in Isle of Wight, Oxfordshire, and Somerset). Those health authorities projected to lose a larger proportion of their general practitioners to these retirements have relatively high levels of need among the population.

The figure shows the proportion of general practitioners by health authority in 1992 that will be lost because of the retirement of South Asian qualifiers against the Benzeval and Judge measure of health authority level population need. ${ }^{15}$

\section{Discussion}

The proportion of general practitioners practising in the NHS who qualified in South Asian medical schools is a relevant health workforce topic because the Indian subcontinent has been a traditional source of medical

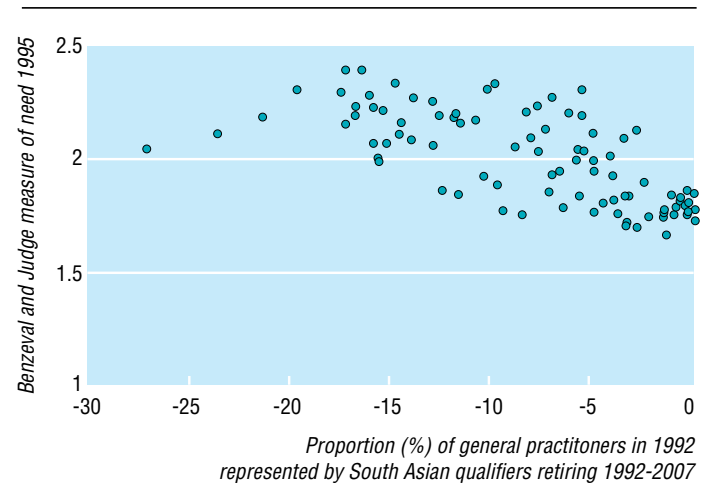

Proportion of general practitioners who qualified in South Asia and will retire by 2007, according to measure of deprivation in practice area. Larger number on vertical axis represents higher need, the average for England being 2.0 in 1995

immigrants for the NHS that is no longer viable given changes in medical licensure. Roughly one in six general practitioners practising in 1992 qualified in South Asia; two thirds will have retired by 2007 . In some health authorities over half of the general practitioners qualified in South Asia, meaning replacement of such doctors will be a major issue that will remain beyond the next decade. Will these posts be difficult to fill?

\section{Difficult posts to fill?}

South Asian qualifiers are more likely to be practising in health authorities that have relatively high patient needs, and South Asian qualifiers have higher than average numbers of patients on their medical list who live in areas designated as deprived. This means that filling their posts may prove to be difficult once they retire as they seem to be located in areas likely to be considered relatively unattractive locations for general practice. Some general practitioners, however, may view large lists and deprivation payments as means of increasing income, raising questions about the quality of care in some high need areas.

There are several reasons why many of the posts vacated by retiring South Asian general practitioners may be less attractive openings; many of the projected vacancies will be in the inner city conurbations, which have traditionally been unattractive to newly qualified general practitioners. (This is probably one of the reasons that many South Asian qualified doctors moved into these areas in the $1970 \mathrm{~s}$ and 1980s.) Despite deprivation payments, the remuneration attainable by inner city general practitioners is often less than that attained by doctors practising in more stable suburban areas. ${ }^{16}$ Finally, the heavier administrative burden resulting from a more mobile population with an excess of mental health problems (including drug abuse), the difficulty in attaining targets for immunisation and cervical screening, and the higher property values in many inner city areas (especially London) may make it difficult to attract new principals.

At present the number of general practitioners moving into a heath authority is closely related to the number of open posts because of the centralised control of practice location maintained by the Medical Practices Committee. No health authority had a net loss of more than seven general practitioners over the period 1990-4. ${ }^{14}$ Health authorities with a higher pro- 
Key messages

- Currently, one in six general practitioners practising full time in the NHS qualified medically in a South Asian medical school; two thirds are likely to retire by 2007

- It is unlikely that doctors who qualify in South Asia will be a source of general practice recruitment in the future

- The posts from which South Asian qualifiers are retiring may be more difficult to fill because they are often in practices in areas of higher need

- There is extreme variation in the proportion of total general practitioners who are South Asian qualifiers; flexibility for policy responses should be maintained

portion of South Asian qualified general practitioners, however, will have to deal with a much larger number of potentially unattractive vacancies in the future, and it is difficult to see how these posts will be filled in the short term in the most heavily affected areas.

\section{Possible responses}

A traditional response to a perceived shortage of doctors is to increase the number of medical students. There is some evidence that the government is willing to do this. ${ }^{17}$ Even if they were recruited in the next few years, however, it is unlikely that the new intake of medical students would be ready to enter general practice in large enough numbers within the next 10 years to deal with this problem completely (even if it is assumed that this cohort chooses general practice in large numbers as opposed to other specialties). In much the same way as South Asian qualifiers filled a staff shortage in the NHS in the 1970s, doctors from the countries of the European Union which produce surplus doctors could replace the retiring South Asian doctors. This is not without its problems. Many South Asian doctors have faced considerable discrimination in the United Kingdom, ${ }^{18-20}$ and doctors from many European countries (especially Eastern European countries) may face similar problems unless mechanisms are in place to prevent this happening.

An alternative mechanism to deal with the perceived shortfall would be to increase the number of non-medically qualified staff able to work in general practice. The experience of nurse practitioners and physician assistants in the United States and in some instances in the United Kingdom suggests that they may be able to work as part of a primary care team in general practice. ${ }^{21}$ By extending the role of physicians and allowing doctors to have larger list sizes it may be possible to reduce the number of doctors that need to be replaced. Government plans to increase flexibilities around employment of general practitioners may also help by keeping some doctors from leaving general practice altogether. Whichever strategy is ultimately chosen, decisions will have to be made soon because in terms of workforce planning 10 years is a relatively short time and the projected decline in numbers of general practitioners in some health authorities could create problems in the delivery of medical services to some of the areas of highest need in England and Wales.

\section{What next?}

A two pronged approach is probably the best way forward. Firstly, health authorities need to assess their supply of general practitioners and determine whether the retirement of South Asian qualifiers is likely to imply special challenges in the years to come; for some areas there is no problem. This suggests that NHS policy should allow for discretion and local initiative in the diagnosis and planning of remedial steps to deal with a present or future problem in filling posts vacated by South Asian qualifiers. Secondly, broad policy decisions related to immigration of doctors need to be debated and made. Individual health authorities and the NHS as a whole should consider what opportunities or difficulties the increasing linkage among European Union member states will imply for filling these posts. Can and should doctors from other European Union states fill in some of the slack or should the United Kingdom have as its goal self sufficiency in terms of its general practitioner workforce? Such broad policy decisions should be discussed now to allow for a comprehensive policy to be in place as general practitioners who qualified in South Asia and emigrated to the NHS in the 1960s and 1970s begin to retire over the next decade.

We thank Julie-Ann Quayle, who conducted analyses of the general practitioner census data as part of this project.

Contributors: DHT obtained the general practitioner census data and other data used, completed exploratory analysis of the data, interpreted the results, and wrote the first and final drafts of the paper. He is the guarantor of this work. AE had the initial idea for the study, supervised preliminary analysis of the data, and wrote revisions of the paper.

Funding: This research was funded by the core grant of the National Primary Care Research and Development Centre, University of Manchester, from the Department of Health.

Competing interests: None declared.

1 General Medical Services Committee. Medical workforce task group report. London: British Medical Association, 1996.

2 Review Body on Doctors' and Dentists' Remuneration. Twenty fifth report, 1996. London: HMSO, 1996.

3 Richards P, McManus C, Allen I. British doctors are not disappearing: but career patterns are changing. BMJ 1997;314:1567-8.

4 Petchey R, Williams J, Baker M. Junior doctors, medical careers and general practice. Nottingham: Nottingham Primary Care Research Unit, Department of General Practice, University of Nottingham, 1996.

5 Anon. NHS must train 150 doctors for 100 GPs. GP News 1996 Jul 19:2.

6 Lambert TW, Goldacre MJ, Edwards C, Parkhouse J. Career preferences of doctors who qualified in the United Kingdom in 1993 compared with those of doctors qualifying in $1974,1977,1980$, and 1985. BMJ 1996;313:19-24.

7 Taylor Jr D, Leese B. Recruitment, retention, and time commitment change of general practitioners in England and Wales, 1990-4: a retrospective study. BMJ 1997;314:1806-10.

8 Parkhouse J. Commentary: there is urgent need to raise recruitmenteven to stand still. BMJ 1997;314:1890.

9 British Medical Association. Core values for the medical profession in the 21st century. London: BMA, 1995.

10 Lambert TW, Goldacre MJ, Parkhouse J. Intentions of newly qualified doctors to practise in the United Kingdom. BMJ 1997;314:1591-2.

11 Parkhouse J. Intake, output, and drop out in United Kingdom medical schools. BMJ 1996;312:885.

12 McManus IC. Drop out rate in medical schools seems reasonable. BMJ 1996;313:173.

13 Taylor Jr D, Leese B. Partnership changes in English general practice from 1990-1994.J Pub Health Med 1997;19:341-6.

14 Taylor Jr D, Leese B. General practitioner turnover and migration in the NHS: 1990-94. Br J Gen Pract 1998;48:1070-2.

15 Benzeval M, Judge K. Access to health care in England: continuing inequalities in the distribution of GPs. J Pub Health Med 1996;18:33-40.

16 Leese B, Bosanquet N. High and low incomes in general practice. BMJ 1989;298:932-4.

17 Department of Health. Extra 1000 medical students every year by 2005. London: Department of Health, 1998. (Press release 98/301.)

18 Smith DJ. Overseas doctors in the National Health Service. London: Policy Studies Institute, 1980.

19 Esmail A, Everington S. Racial discrimination against doctors from ethnic minorities. BMJ 1993;306:691-2.

20 Esmail A, Everington S. Complaints may reflect racism. BMJ 1994;308:1374.

21 Clawson DK, Osterweis M, eds. The roles of physician assistants and nurse practitioners in primary care. Washington: Association of Academic Health Centers, 1993.

(Accepted 20 October 1998) 